\title{
Measurement of surface ozone and its precursor NOx over urban and rural locations in Kannur- a tropical coastal site in India
}

Nishanth.T and M. K .Satheesh Kumar

Department of Atmospheric Science, Kannur University, Kannur, Kerala- 670 567, India nisthu.t@gmail.com

\begin{abstract}
Diurnal variations of surface ozone and NOx (oxides of nitrogen) at Kannur University Campus (12.3N, 75.4E), a rural location and at Kannur Town, an urban location in Kannur (11.9N, 75.3E), a tropical coastal site in the state of India have been studied during winter months of 2009 and 2010. Being an industrially weak area, the study has the uniqueness to reveal the surface ozone production from its prominent precursor NOx at this site lying along the coastal belt of the Arabian Sea. The maximum value of surface ozone has been observed during day time and minimum during night at two locations. The rate of production and loss of surface ozone is higher at a rural location than an urban location in the same region. This highlights the substantial difference in the ozone chemistry over these two locations.

Keywords: Surface Ozone, NOx, Diurnal Variation, Air pollution
\end{abstract}

\section{Introduction}

The composition of the Earth's atmosphere has been changed by human activity and some of these changes are harmful to human health, crops and ecosystems. The atmosphere contains $\mathrm{N}_{2}, \mathrm{O}_{2}$ and $\mathrm{Ar}$ as major constituents. However there are many other gases which are in low quantities but play an important role in its chemistry and radiation budget. These are divided into two different levels of concentrations, viz minor constituents and trace gases. Ozone is the most important trace gas, which has been talked about ever since it was discovered in the atmosphere (Lal S 2007). Ozone concentration is found to be more in the stratosphere in the height range of 20$28 \mathrm{Km}$ depending on the latitude. In fact, the presence of ozone results in the stratospheric thermal structure by absorbing the harmful solar UV radiation. In the troposphere, ozone is a green house gas which can influence climate and its higher levels even can deleterious effects on the human health and plants (Crutzen 1974). The only mechanism of ozone production is the recombination of atomic oxygen $\left(\mathrm{O}^{3} \mathrm{P}\right)$ with the oxygen molecule. Atomic oxygen $\left(\mathrm{O}^{3} \mathrm{P}\right)$ necessary for ozone production is mainly provided by the photodissociation of $\mathrm{NO}_{2}(\lambda<410 \mathrm{~nm})$ in the troposphere where as in the stratosphere it comes from the photodissociation of $\mathrm{O}_{2}(\lambda<242 \mathrm{~nm})$ (Chapman 1930; Naja 2004). The production of surface ozone plays a crucial role in the chemistry of the earth's atmosphere, though it is a minor constituent in terms of its abundance (Naja et al., 2004; Subbaraya \& Shyam Lal, 1998). Surface ozone does not have direct natural sources, but it is produced in the atmosphere mainly due to its precursors emitted by the increased human activities (Purkait et al., 2009). In the lower troposphere, surface ozone production takes place by photo oxidation of $\mathrm{CH}_{4}$, $\mathrm{CO}$ and NMHCs in the presence of sufficient amount of NOx (Lal et al., 2000). The most important nitrogen oxides are nitrogen monoxide (NO or nitric oxide) and nitrogen dioxide $\left(\mathrm{NO}_{2}\right)$. Main sources of Nitrogen oxide $\left(\mathrm{NO}_{\mathrm{x}}\right)$ in the atmosphere is due to fossil fuel combustion, fires, microbial soil emissions, lightning, aircraft and oxidation of biogenic $\mathrm{NH}_{3}$ (Kleinman 1994). Many studies around the globe have reported that the surface ozone in rural locations near the industrial areas have increased significantly (Khemani et al., 1995; Debaje and Kakade 2006). It has been revealed from the satellite data that the NOx abundance over Kerala shows an increasing trend over the past few years (Satheesh et al., 2010; Sachin et al., 2009). To retrieve the impact of surface ozone on the radiative forcing of climate, its variation has to be precisely studied using ground based observations. Recently, diurnal and seasonal variations of surface ozone over south Kerala have been successfully classified (Nair et al., 2002) and the results are quite promising to reveal the variation of surface ozone over Kerala. Subsequently, to explore the photochemical production of surface ozone from its prominent precursor NOx over north Kerala, a study has been initiated in Kannur University to reveal the diurnal variability of surface ozone at two sites in Kannur region which is located along the coastal belt of Arabian Sea.

Surface ozone is mainly produced by the photo dissociation of $\mathrm{NO}_{2}$ in the day time as
$\mathrm{NO}_{2}+\mathrm{hv}(\lambda<410 \mathrm{~nm})$
$\mathrm{O}\left({ }^{3} \mathrm{P}\right)+\mathrm{O}_{2}+\mathrm{M}$
$\rightarrow \mathrm{NO}+\mathrm{O}$
$\left({ }^{3} \mathrm{P}\right)$----- $(\mathrm{R} 1)$
$\rightarrow \mathrm{O}_{3}+\mathrm{M} \quad---(\mathrm{R} 2)$

The ozone thus generated can be removed by the titration with $\mathrm{NO}$ as

$$
\mathrm{O}_{3}+\mathrm{NO} \quad \rightarrow \mathrm{NO}_{2}+\mathrm{O}_{2} \quad----(\mathrm{R} 3)
$$

Locations of study and the general meteorology

The two locations selected for observations are shown in Fig.1. Kannur University Campus (KUC) is located in the northern part of Kannur, which is close to Arabian Sea and is situated in an open land. Location at KUC receives plenty of sunshine throughout the day without any shadows. Being this a pristine and unpolluted area, the study would reveal the amount of ozone produced from its various precursors and its chemistry at this location. This analysis will be vital to analyze the radiative processes that have significant impact on the climate changes. Another site is at Kannur Town (KT) which is placed by the side of a national highway where vehicular traffic is very high. Indian J.Sci.Technol. 
Indian Journal of Science and Technology

Fig. 1. Locations of two sites of observation

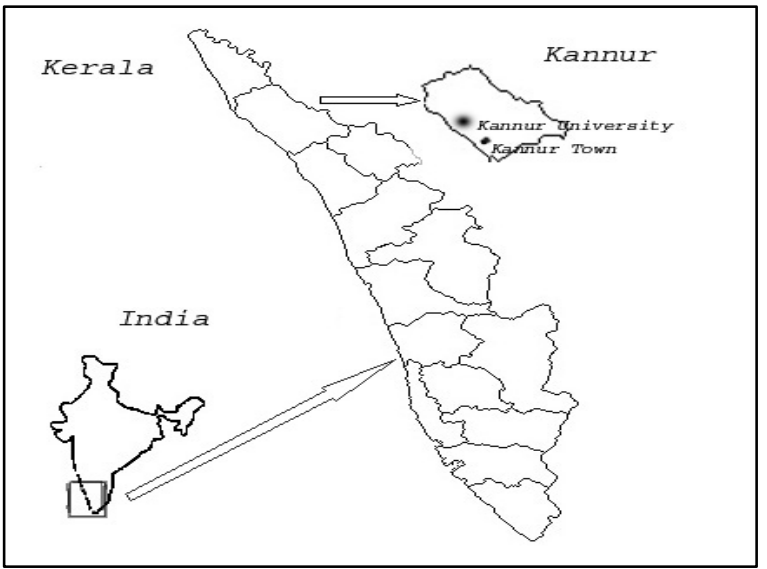

The months December, January and February are characterized by winter at this location and experiences easterly wind during this season. The average weather like relative humidity, solar flux, surface pressure, wind speed, wind direction, rain fall at Kannur during the study period has been collected from a local automatic weather station which is one of the stations of Meteorological and Oceanographic Satellite Data Archival Centre (MOSDAC) established by Indian Space Research Organization at Kannur. The time series variation of solar radiation, surface temperature, relative humidity and wind speed at

Fig.2. Time series variation of solar radiation at Kannur
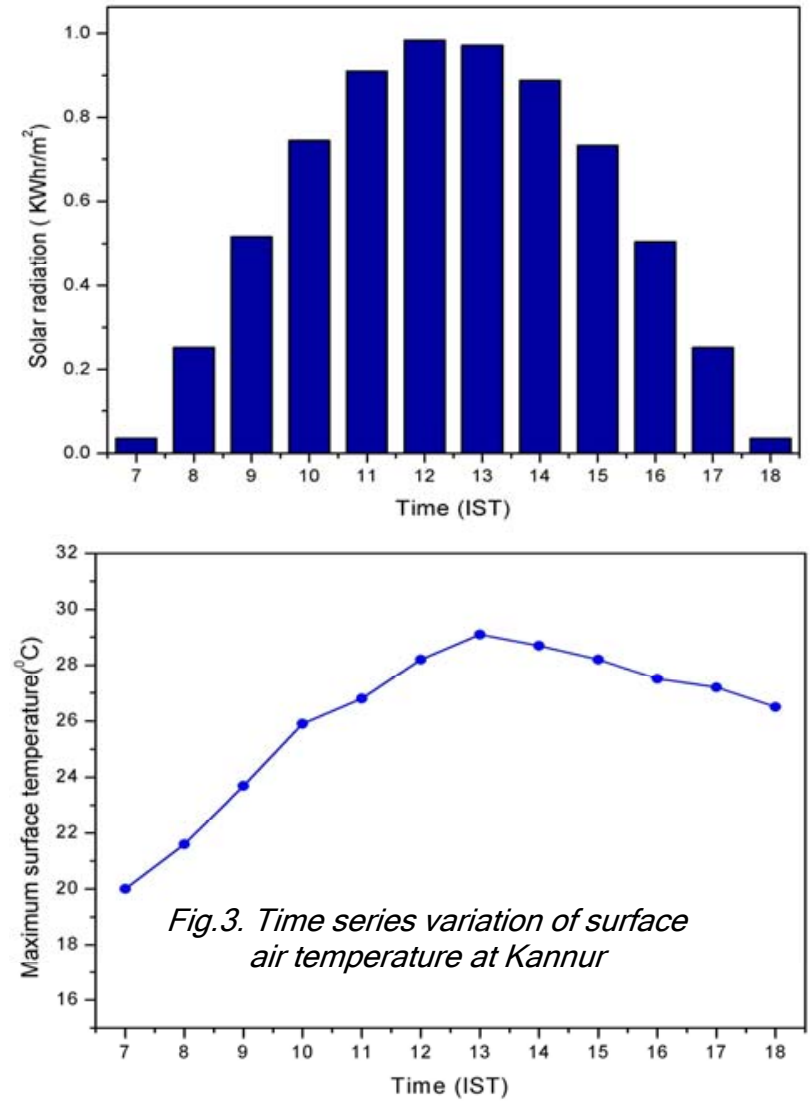

Research article

COIndian Society for Education and Environment (iSee)
Vol. 3 No. 12 (Dec 2010)

ISSN: 0974- 6846

Kannur during the period of observations in winter months is exposed in Fig. 2, 3, 4 \& 5 and the average weather data is shown in the following Table 1.

Table1. Average weather data at Kannur during winter

\begin{tabular}{|l|l|}
\hline Meteorological parameters & $\begin{array}{l}\text { Average data during day } \\
\text { time }\end{array}$ \\
\hline Relative Humidity & $63.52 \%$ \\
\hline Total Solar flux & $0.568 \mathrm{KW} \mathrm{hr} / \mathrm{m}^{2}$ \\
\hline Surface pressure & $1004.4 \mathrm{mb}$ \\
\hline Wind speed & $3.89 \mathrm{~m} / \mathrm{s}$ \\
\hline Wind direction & $270^{0}($ Easterly winds) \\
\hline Surface temperature & $26.11^{\circ} \mathrm{C}$ \\
\hline Rain fall & $\mathrm{Nil}$ \\
\hline
\end{tabular}
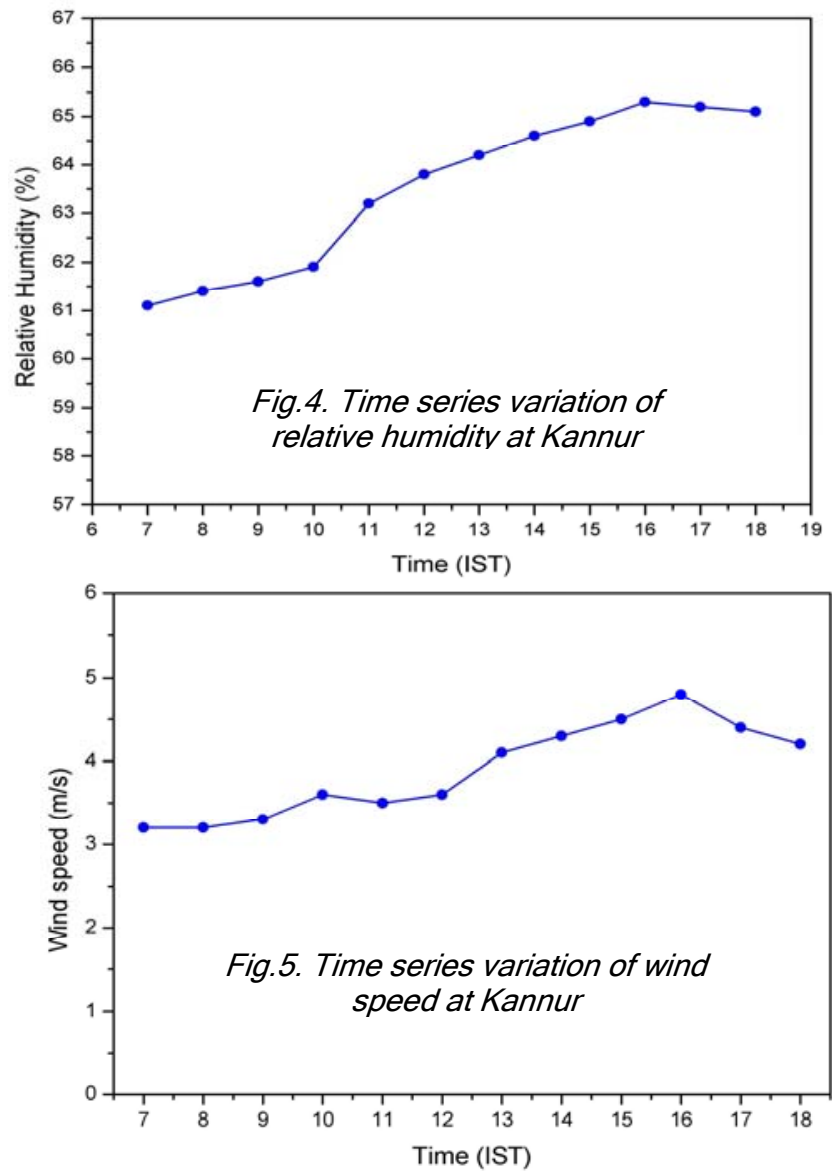

Instruments used for the study

The concentrations of surface ozone and NOx were measured simultaneously with instruments obtained from Environment S.A., France. The concentrations of ozone was measured using the analyzer (Model $\mathrm{O}_{3} 42 \mathrm{M}$ ). The principle of measurement is based on the absorption of UV at $253.7 \mathrm{~nm}$ by ozone present in the sample air. Calibration of the analyzer was performed at regular interval using ozone free air and pure ozone produced using appropriate gas generators. Its low detectable limit is $0.4 \mathrm{ppbv}$ with minimum response time of 20 seconds. The analyzer is provided with an in-built correction facility for temperature and pressure variations as well as the intensity fluctuations of the lamp. 
The total $\mathrm{NOx}\left(\mathrm{NO}+\mathrm{NO}_{2}\right)$ was monitored with standard chemiluminescent analyzer (Model AC 31M) based on the measurement of chemiluminescence (at $630 \mathrm{~nm}$ ) produced by the oxidation reaction of $\mathrm{NO}$ of the sample gas with $\mathrm{O}_{3}$. There is also provision for separating $\mathrm{NO}$ and $\mathrm{NO}_{2}$ components in the NOx data. The lower detection limit of the detector is $0.35 \mathrm{ppbv}$ with minimum response time 20 seconds. The calibration of the system was done using a reference standard NO in cylinders obtained from E.SA Mumbai. These analysers are based on currently accepted technique and are widely being employed all over the globe.

\section{Diurnal variation of $\mathrm{O}_{3}$ and $\mathrm{NOx}$ at $\mathrm{KUC}$}

Diurnal profiles of surface ozone and NOx observed at KUC during winter is shown in Fig. 6 \& 7.The vertical lines are one sigma standard deviation. It is observed that surface ozone production at KUC during night time is quite low. The ozone concentration starts to increase during 0800-0900 $\mathrm{hr}$ (IST) at all days of observations in winter months. The mixing ratio reaches a maximum during noon time around $1400-1500 \mathrm{hr}$ at which the production of ozone is a maximum resulted from the photolysis of $\mathrm{NO}_{2}$ as represented by reactions (R1) and (R2). During the late evening hours, around $1800-2000 \mathrm{hr}$ the ozone concentration tends to decrease and reaches to a minimum. Low value of $\mathrm{O}_{3}$ during night could mostly be due to the absence of photo chemical reaction and its destruction through titration with $\mathrm{NO}$ as represented by reaction (R3). This is due to the fresh release of pollutant during the day from vehicular traffic and subsequent photo oxidation of $\mathrm{NO}_{2}$.

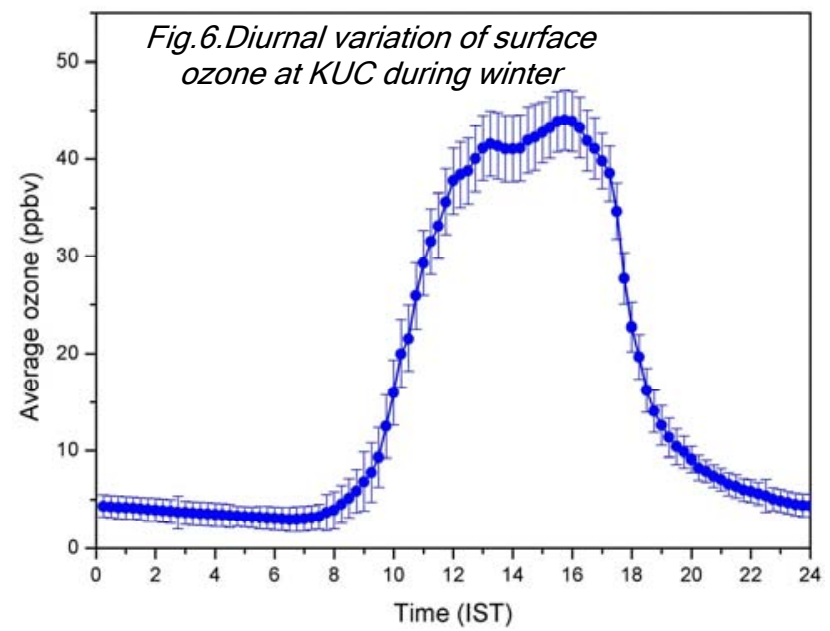

The NOx $\left(\mathrm{NO}+\mathrm{NO}_{2}\right)$ concentration reaches its minimum level in the afternoon, at which the production of ozone is maximum. From the figures 6 and 7 a clear anti correlation is observed for the abundances of ozone and NOx over the KUC during winter months. The average value of day time ozone is $26.92 \mathrm{ppbv}$ and maximum value at $1500 \mathrm{hr}$ is $45 \mathrm{ppbv}$ and that of night time is $3.62 \mathrm{ppbv}$. The mean value of day time NOx is $1.65 \mathrm{ppbv}$ and that of night time is $2.73 \mathrm{ppbv}$. During $0800-1100 \mathrm{hr}$, the rate of change of ozone is $10 \mathrm{ppbv} / \mathrm{hr}$, whereas in the evening, $1700-1900 \mathrm{hr}$, the rate of change of ozone is 17.7ppbv/hr.

\section{Diurnal variation $\mathrm{O}_{3}$ and $\mathrm{NOx}$ at $\mathrm{KT}$}

Diurnal profiles of surface ozone and NOx during winter season at KT is shown in the figures 8 and 9 . It is observed a similar profile of ozone and NOx variations at $\mathrm{KUC}$ as well; however, there is a significant change in the production and loss rates of ozone and NOx. The concentration of ozone during this period is found to be increased from a minimum value of $9 \mathrm{ppbv}$ around 0830 $\mathrm{hr}$, to a maximum value of $36 \mathrm{ppbv}$ around $1200-1300 \mathrm{hr}$. In the evening, around $1800-2000 \mathrm{hr}$, the ozone concentration tends to reach its lowest value of 5ppbv. Higher levels of NOx during day time are mainly due to extensive vehicular exhaust at this location. The average value of day time ozone at this site is $24.21 \mathrm{ppbv}$ with maximum of $35 \mathrm{ppbv}$ at $1400 \mathrm{hr}$ and during night time is $5.23 \mathrm{ppbv}$. The average value of day time NOx is found to be $6.81 \mathrm{ppbv}$ and that of night time is $5.41 \mathrm{ppbv}$. During $0800-1100 \mathrm{hr}$, the rate of increase of ozone is $4.6 \mathrm{ppbv} / \mathrm{hr}$, whereas during in the evening, $1700-1900 \mathrm{hr}$, the rate of change of ozone is $5.7 \mathrm{ppbv} / \mathrm{hr}$. Table 2 shows the rate of change of ozone and NOx at these two locations.

Table.2. Observed rate of change of ozone at two sites

\begin{tabular}{|l|l|l|}
\hline Locations & $\begin{array}{l}0800-1100 \mathrm{hrs} \\
(\mathrm{ppbv} / \mathrm{hr})\end{array}$ & $\begin{array}{l}1700-1900 \mathrm{hrs} \\
(\mathrm{ppbv} / \mathrm{hr})\end{array}$ \\
\hline KUC & 10.0 & -17.7 \\
\hline KT & 4.6 & -5.7 \\
\hline
\end{tabular}

\section{Discussion}

The diurnal variations of surface ozone and NOx at KUC and KT have been observed and it is found a significant difference in the ozone production and its loss rates at these two locations. This reveals that ozone production and lapse rates are much higher at KUC than that at KT. It is further observed a small decline in the ozone concentration during noon time at these two locations and it may be due to the hectic convective activity on the ground at noon time which can reduce the ozone mixing ratio till it gets stabilized. At KUC, the production and destruction of ozone are quite sharp, while at $\mathrm{KT}$, the period over which maximum ozone concentration existing is less compared to that in KUC. This is due to the abundance of other prominent pollutants present over KT by which they severely affect the mixing of ozone with the ambient air. The observed profile of ozone variation over KUC is quite similar to that have been reported earlier in the case of a rural environment in India where the production of ozone is higher than urban locations (Londhe et al., 2008). This observation could be further substantiate only by accounting the role of other prominent ozone precursors like $\mathrm{CO}, \mathrm{CH}_{4}$ and VOCs present over these two locations. In this connection, attempts are being imitated to explore the significant role of these trace gases on the production and loss of surface ozone at these two locations.
Research article

COIndian Society for Education and Environment (iSee)
"Ozone monitoring" http://www.indjst.org
Nishanth \& Satheesh Kumar Indian J.Sci.Technol. 
Indian Journal of Science and Technology
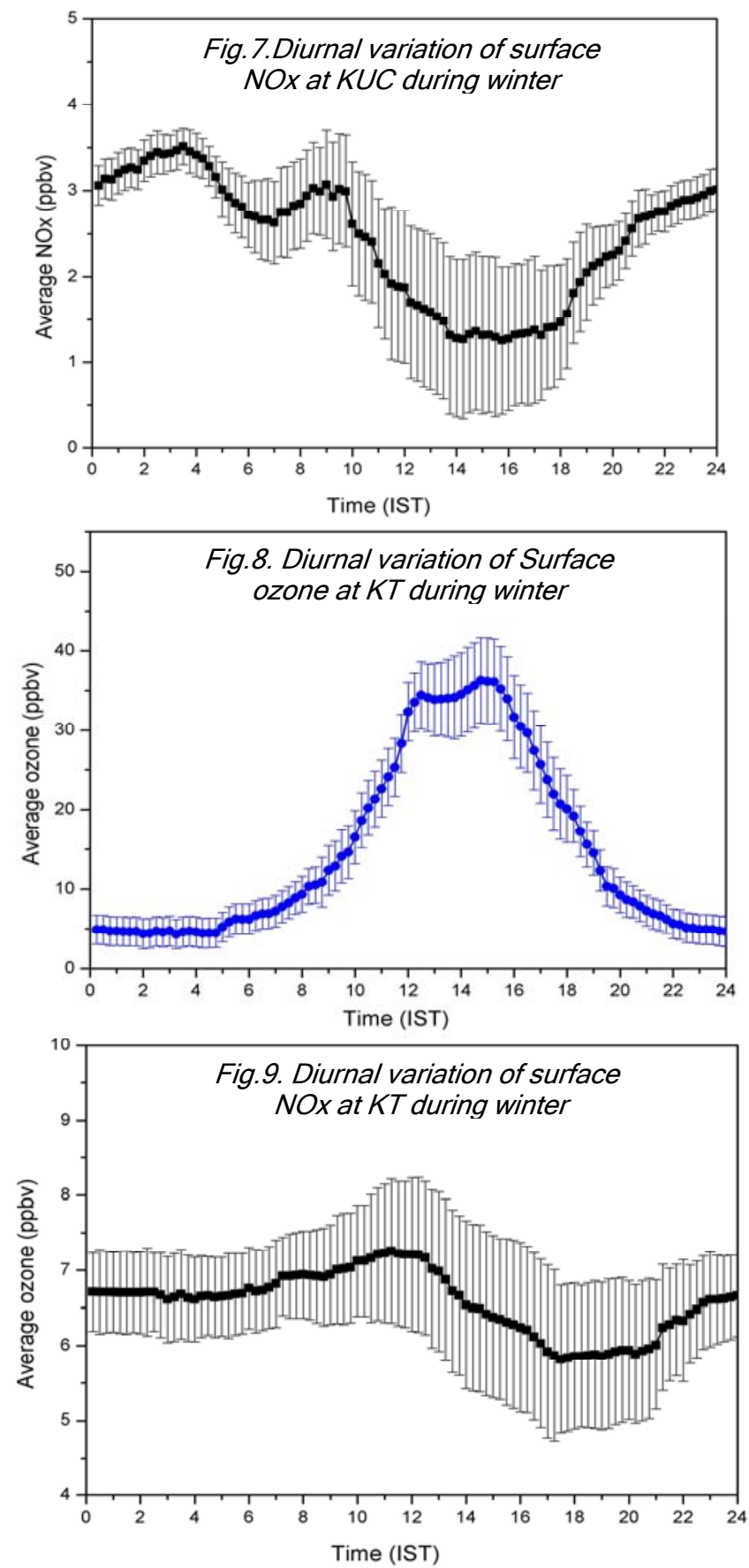

\section{Conclusions}

This study is the first attempt in this region which is lying along the coastal belt of the Arabian Sea to explore the production of surface ozone from its prominent precursor NOx during winter months. The variability of surface ozone and its precursor NOx have been monitored at KUC and KT during winter months of 2009 and 2010. These two sites are separated by $20 \mathrm{Km}$, yet the variations of surface ozone and NOx at the two sites differ significantly. The day time ozone production at KUC is found much higher than that at KT during the period of observation. It is revealed that the ozone production and
Vol. 3 No. 12 (Dec 2010)

ISSN: 0974- 6846

loss rates at KUC are much higher than at KT. This may be due to the enhanced loss rate of ozone in rich NOx environment. The rapid production and loss rates of ozone observed at KUC are mainly due to the less amount of pollution. Relatively low production and loss rate of ozone at KT gives a clear indication that $\mathrm{KT}$ is a polluted site, where other prominent precursors play a major role in the chemistry of ozone.

\section{Acknowledgement}

The authors gratefully acknowledge the financial assistance rendered by the Kerala State Council for Science Technology and Environment (KSCSTE) through a research project. Part of this work is carried out by the support of ISRO-GBP under AT-CTM programme. We are grateful to the anonymous reviewers for their critical review and suggestions for improvement of this manuscript.

References

1. Chapman S (1930), On ozone and atomic oxygen in the upper atmosphere, Phil Mag, 10, 369

2. Crutzen PJ (1974) Photochemical reactions initiated by and influencing ozone in unpolluted tropospheric air. Tellus. 26, 48-57.

3. Debaje and Kakade (2006). Measurement of surface ozone in rural site of India. Aerosol \& Air Quality Res. 6 (4), 444-465.

4. Khemani LT, Momin GA, Rao PSP, Vijaykumar R and Safai PD (1995) Study of ozone behaviour at urban and forested sites in India. Atmospheric Environ.29,2021-2024.

5. Kleinman L (1994) Ozone formation at a rural site in the southeastern United States. J.Geophys. Res.99,3469-3482

6. Lal S, Naja M and Subbaraya BH (2000) Seasonal variations in surface ozone and its precursors over an urban site in India. Atmospheric Environ. 34, 2713-2724.

7. Lal S (2007), Trace gases over the Indian region, Indian J. of Radio \& Space Physics .36, 556-570.

8. Londhe AL, Jadhav DB, Buchunde PS and Kartha M J (2008). Surface ozone variability in the urban and nearby rural locations of tropical India. Curr. Sci. 95: 1724-1729.

9. Nair PR, Chand D, Lal S, Modh KS, Naja M, Parameswaran K, Ravindran S and Venkataramanai S (2002) Temporal variations in surface ozone at Thumba $\left(8.6^{\circ} \mathrm{N}, 77^{0} \mathrm{E}\right)$ - a tropical coastal site in India. Atmospheric Environ.36, 603-610.

10. Naja M, Chand D, Sahu L and Lal S (2004) Trace gases over marine regions around India. Indian J. Marine Sci. 33, 95-106.

11. Purkait NN, Sen S and Chakrabarty DK (2009) Surface ozone and its precursors at two sites in the northeast coast of India. Indian J. Radio \& Space Phys. 38, 86-97.

12. Sachin D Ghude, Van der ARJ, Beig G, Fadnavis and Polade SSD (2009) Satellite derived trends in $\mathrm{NO}_{2}$ over the major global hotspot regions during the past decade and their inter comparison. Environ. Pollution. 157, 18731878.

13. Satheesh Kumar MK, Nishanth T, Praseed KM and Sheela Joseph M (2010) The significant role of CO and NOx in the ozone chemistry. Recent Res. in Sci. \& Technol. 3, 1-5.

14.Subbaraya BH and Shyam Lal (1998) Tropospheric chemistry. PINSA. 64, 277-288.
Research article

CIndian Society for Education and Environment (iSee)
"Ozone monitoring"

http://www.indjst.org
Nishanth \& Satheesh Kumar Indian J.Sci.Technol. 